\title{
Neutralizing Antibody Response in Dogs and Cats Inoculated with Commercial Inactivated Rabies Vaccines
}

\author{
Rikiya SHIRAISHI ${ }^{1 *}$, Masaaki NISHIMURA ${ }^{1)}$, Ryuji NAKASHIMA ${ }^{1)}$, Chiho ENTA $^{1)}$ and Norio HIRAYAMA ${ }^{2)}$ \\ 1) Research Institute for Animal Science in Biochemistry \& Toxicology, 3-7-11 Hashimotodai, Midori-ku, Sagamihara, Kanagawa \\ 252-0132, Japan \\ 2) Azabu University, 1-17-71 Fuchinobe, Chuo-ku, Sagamihara, Kanagawa 252-5201, Japan
}

(Received 28 June 2013/Accepted 17 December 2013/Published online in J-STAGE 31 December 2013)

ABSTRACT. In Japan, the import quarantine regulation against rabies has required from 2005 that dogs and cats should be inoculated with the rabies vaccine and that the neutralizing antibody titer should be confirmed to be at least 0.5 international units (IU)/ml. The fluorescent antibody virus neutralization (FAVN) test is used as an international standard method for serological testing for rabies. To achieve proper immunization of dogs and cats at the time of import and export, changes in the neutralizing antibody titer after inoculation of the rabies vaccine should be understood in detail. However, few reports have provided this information. In this study, we aimed to determine evaluated, such changes by using sera from experimental dogs and cats inoculated with the rabies vaccine, and we tested samples using the routine FAVN test. In both dogs and cats, proper, regular vaccination enabled the necessary titer of neutralizing antibodies to be maintained in the long term. However, inappropriate timing of blood sampling after vaccination could result in insufficient detected levels of neutralizing antibodies.

KEY WORDS: canine, feline, rabies, vaccine.

doi: 10.1292/jvms.13-0335; J. Vet. Med. Sci. 76(4): 605-609, 2014

Rabies is caused by the rabies virus and is a fatal disease that has a wide range of mammalian hosts, including humans [9]. The fatality rate is nearly $100 \%$ in infected humans with symptoms. Developing countries in Asia and Africa have the highest prevalence of rabies, and more than 50,000 people die of rabies per annum worldwide [4]. Because the rabies virus can infect many animal species, eradication of the virus is thought to be impractical. The main cause of human infection by rabies virus is a bite from rabies-infected animals, such as dogs and cats. Thus, the most effective measure for preventing rabies outbreaks is the vaccination of these animals [2].

In Japan, when dogs and cats are imported from rabiesepidemic areas, the rabies quarantine system requires that these animals are inoculated with an inactivated rabies vaccine twice with at least 30 days between injections after they reach the age of 91 days and the rabies neutralizing antibody titer in the serum has to be confirmed as at least 0.5 international units $(\mathrm{IU}) / \mathrm{m} l$. This certification of neutralizing antibody titer is valid for two years from the date of blood sampling following vaccination, if the animal is inoculated with the third vaccine at one year after the second vaccination.

The titer of $0.5 \mathrm{IU} / \mathrm{m} l$ or more is considered to provide

*Correspondence to: Shiraishi, R., Research Institute for Animal Science Biochemistry \& Toxicology, 3-7-11 Hashimotodai, Midori-ku, Sagamihara, Kanagawa 252-0132, Japan.

e-mail: r_shiraishi@riasbt.or.jp

(C2014 The Japanese Society of Veterinary Science

This is an open-access article distributed under the terms of the Creative Commons Attribution Non-Commercial No Derivatives (by-nc-nd) License $<$ http://creativecommons.org/licenses/by-nc-nd/3.0/>. adequate protection against rabies [14]. Almost countries accept this threshold for import quarantine regulation of dogs and cats. Therefore, dogs or cats brought into other countries from Japan should present titers equal or more than $0.5 \mathrm{IU} /$ $\mathrm{m} l$.

Our laboratory, which is registered as a laboratory for rabies neutralizing antibody testing by Ministry of Agriculture, Forestry and Fisheries, conducts rabies neutralizing antibody testing using the fluorescent antibody virus neutralization (FAVN) test for approximately 3,000 serum samples per year, mostly from dogs and cats. Currently, approximately $5 \%$ of all serum samples tested in our laboratory do not pass the test. However, the cause is still not clear. Therefore, detailed analysis of changes in neutralizing antibody titer after inoculation of dogs and cats with the rabies vaccine is necessary.

Therefore, in this study, we aimed to evaluate the change in the sera of experimental dogs and cats inoculated with the rabies vaccine and routine sera for the FAVN test.

Ten male or female 13-to 24-month-old beagle dogs were purchased from Narc (Chiba, Japan), and 10 male or female 6-to 12-month-old cats (mixed breed) were purchased from Liberty Research Inc., (Waverly, NY, U.S.A). All these animals had not been inoculated with any rabies vaccine. They were housed in separate cages and given commercial feed for experimental animals (Labo D Stock, Nosan Corporation, Kanagawa, Japan) and tap water during the test period. This study was approved by the Animal Care and Use Committee of the Research Institute for Animal Science in Biochemistry \& Toxicology.

Each of 2 commercial inactivated tissue culture rabies vaccines (A and $B$ ) that contained no adjuvant was inoculated twice with a 33-day (in dogs) or 35-day (in cats) interval 
into the neck muscle of 5 dogs and 5 cats. To determine longterm changes in the titer of the rabies neutralizing antibody, a third vaccination was conducted 12 months after the second vaccination according to the rabies quarantine system of Japan.

For all the animals, serum samples were collected from each animal at the following time points: before the first vaccination (day 0); 7 (only in cats), 14, 21 and 28 days after the first vaccination; 7, 14, 21 and 28 days after the second and third vaccinations; and every month from 3 to 25 months after the first vaccination (until 12 months after the third vaccination).

The rabies neutralizing antibody titer of the test sera was measured by the FAVN test according to the procedure published in the OIE (World Organisation for Animal Health) manual [13]. In brief, the test sera and rabies neutralizing antibody-positive $(0.5 \mathrm{IU} / \mathrm{m} l)$ and rabies neutralizing antibody-negative reference sera supplied by the Nancy laboratory of the French Agency of Food, Environmental and Occupational Health \& Safety (ANSES) were diluted 3 times in Dulbecco's modified Eagle medium (D-MEM) supplemented with $10 \%$ fetal calf serum (FCS). The mixtures were heat-inactivated for $30 \mathrm{~min}$ at $56^{\circ} \mathrm{C}$ (dog samples) and $65^{\circ} \mathrm{C}$ (cat samples). In a 96-well cell culture microplate, $50 \mu \mathrm{l}$ of rabies virus (strain CVS-11, ATCC number VR 959) solution diluted to $100 \mathrm{TCID}_{50} / \mathrm{m} l$ with D-MEM containing $10 \% \mathrm{FCS}$ was added to $50 \mu \mathrm{l}$ of each threefold dilution of serum and incubated for $1 \mathrm{hr}$ in $5 \% \mathrm{CO}_{2}$ at $37^{\circ} \mathrm{C}$. Then, $50 \mu \mathrm{l}$ of a BHK21 cell (BHK-21 C13, ATCC number CCL-10) suspension at $4 \times 10^{5}$ cells $/ \mathrm{ml}$ in D-MEM containing $10 \% \mathrm{FCS}$ was added to all the tested wells and incubated for $48 \mathrm{hr}$ in $5 \% \mathrm{CO}_{2}$ at $37^{\circ} \mathrm{C}$. After incubation, all test wells were fixed with $80 \%$ acetone for $30 \mathrm{~min}$ at room temperature and stained using an anti-rabies virus fluorescein isothiocyanate (FITC) -conjugated monoclonal antibody (Fujirebio Diagnostics, Inc., Pennsylvania, Malvern, PA, U.S.A.). The titer in $\mathrm{IU} / \mathrm{m} l$ of each serum sample was calculated as follows: tested serum

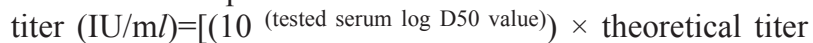
of the positive reference serum $] /(10$ ( $\log$ D50 of positive reference serum)). The term "D50" indicates the median dose in TCID 50 .

For the dog samples, only the results for vaccine A are shown, because the rabies neutralizing antibody response was similar between vaccines $\mathrm{A}$ and $\mathrm{B}$. After the first vaccination, in all cases, the antibody titer reached at least 0.5 $\mathrm{IU} / \mathrm{m} l$ by 2 weeks and leveled off or declined slightly during the next 2 weeks. At 1 or 2 weeks after the second vaccination, the antibody titer increased sharply and reached its peak value (53-1,094 IU/ml) (Fig. 1) and was then maintained at $0.5 \mathrm{IU} / \mathrm{m} l$ or more. At 1 week after the third vaccination, the antibody titer increased and peaked (17.8-277 $\mathrm{IU} / \mathrm{m} l)$, and it was subsequently maintained for at least 4 weeks, after which it decreased gradually, although it was at least $0.5 \mathrm{IU} /$ $\mathrm{m} l$ until the end of the test period (4.5-160 IU/ml) (Fig. 2). These changes were similar to those reported by Ezoe et al. (2007) [5].

In the tests for cats, we have only shown the results for vaccine $\mathrm{A}$ for the same reason we only showed vaccine $\mathrm{A}$ results for dogs. At a week after the first vaccination, the

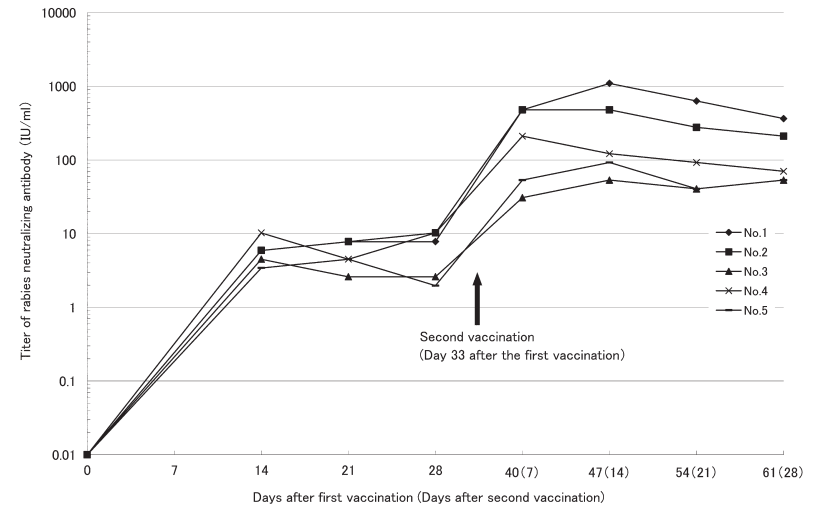

Fig. 1. Weekly evaluation of rabies neutralizing antibody titer in dogs inoculated with commercial rabies inactivated tissue culture vaccine $A$. The vaccine was inoculated on day 0 (first vaccination) and day 33 (second vaccination). Following each vaccination, blood was sampled every 7 days (except on day 7), and the rabies neutralizing antibody titer was measured individually by the FAVN test.

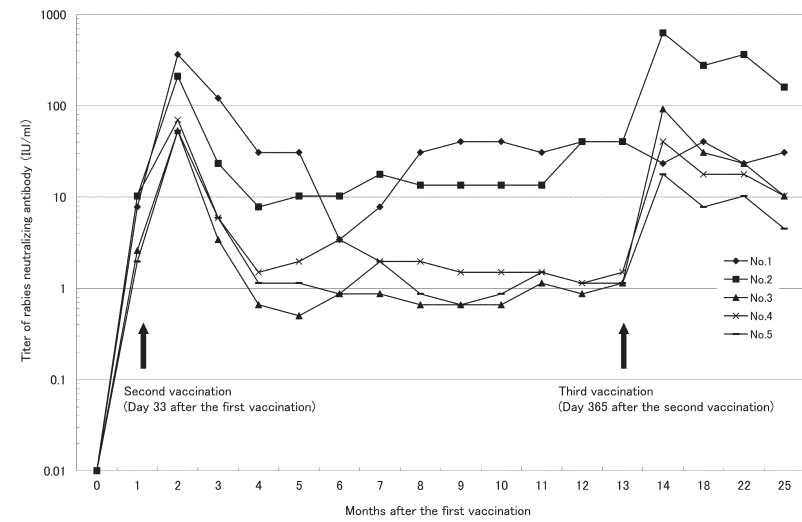

Fig. 2. Monthly evaluation of rabies neutralizing antibody titer in dogs inoculated with commercial rabies inactivated tissue culture vaccine $A$. The vaccine was inoculated on day 0 (first vaccination), day 33 (second vaccination) and day 398 (365 days after the second vaccination) (third vaccination). The monthly titer of rabies neutralizing antibody was measured individually by the FAVN test.

antibody titer increased sharply and reached at least $0.5 \mathrm{IU} /$ $\mathrm{m} l$ in all cases. The peak antibody titer was noted 3 weeks after the first vaccination in most cases and was then maintained until 4 weeks. After the second vaccination, the peak titer was observed at 1 week after injection in most of the cases (70.2-480 IU/ml) (Fig. 3). The third vaccination also induced a remarkable increase in the antibody titer after 1 or 2 weeks in most cases $(160-277 \mathrm{IU} / \mathrm{m} l)$, and the titer was maintained at the same level at 1 year after the third vaccination (53.3-160 IU/ml) (Fig. 4). These changes were similar to those reported by Ezoe et al. (2007) [6].

The present experimental vaccination data clearly demonstrate that the peak antibody titer occurred at 1 or 2 weeks after the second vaccination in both dogs and cats. To validate 


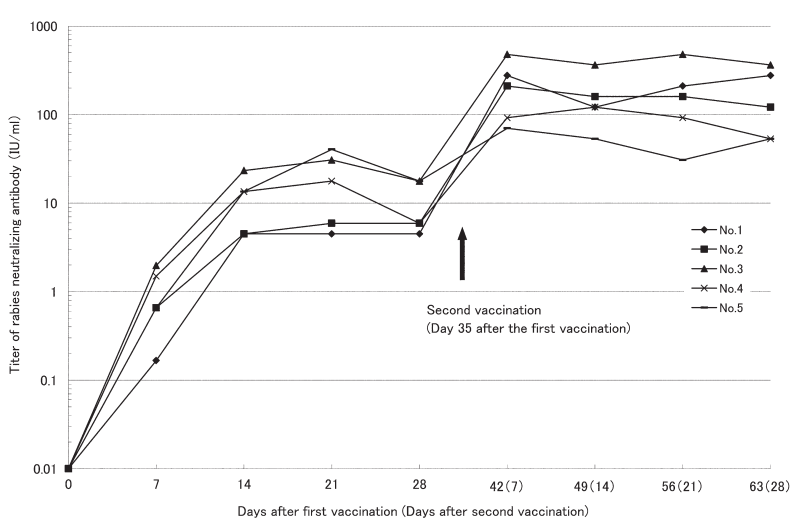

Fig. 3. Weekly evaluation of rabies neutralizing antibody titer in cats inoculated with commercial rabies inactivated tissue culture vaccine $A$. The vaccine was inoculated at day 0 (first vaccination) and day 35 (second vaccination). Following each vaccination, blood was sampled every 7 days, and the rabies neutralizing antibody titer was measured individually by the FAVN test.

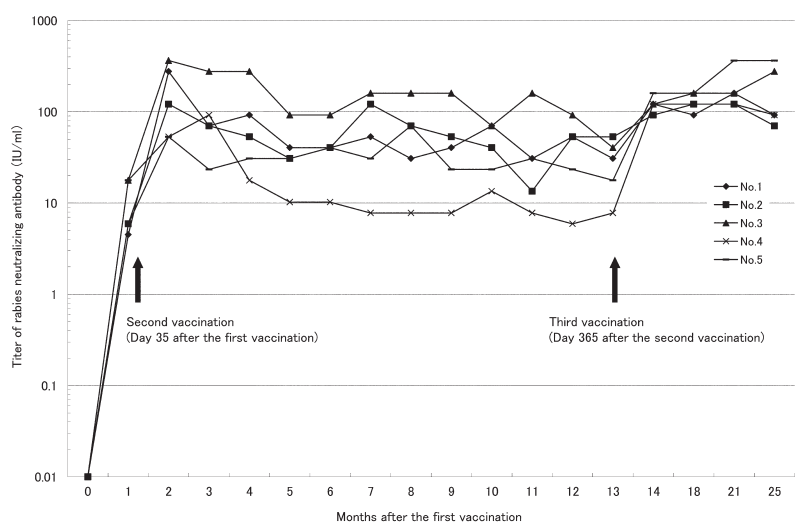

Fig. 4. Monthly evaluation of rabies neutralizing antibody titer in cats inoculated with commercial rabies inactivated tissue culture vaccine $A$. The vaccine was inoculated on day 0 (first vaccination), day 35 (second vaccination) and day 400 (day 365 after the second vaccination) (third vaccination). The monthly titer of rabies neutralizing antibody was measured individually by the FAVN test.

the experimental data, we analyzed data derived from 5,079 serum samples submitted to our laboratory for FAVN testing from 2005 to 2011 . These sera were obtained from 1,795 dogs and 3,284 cats that had been inoculated with commercial rabies inactivated vaccines (made by Japanese or foreign manufacturers) only twice since birth with an interval of at least 30 days between injections. These sera are referred to as "routine dog serum" and "routine cat serum" in this study. Based on the number of days between the first and second vaccinations and the number of days after the second vaccination, the relationship between the neutralizing antibody titer and the pass rate in the FAVN test was investigated. To compare the potency between Japanese vaccine and foreign vaccine, the data were differentiated between vaccines from Japanese (no adjuvant present) and foreign (adjuvantcontaining) manufacturers.

The results for the routine sera are shown in Table 1 (for dogs) and Table 2 (for cats). In both routine dog and cat sera, the peak antibody titer was typically observed between 8 and 21 days after the second vaccination for any interval between the first and second vaccinations in dogs or when the interval between the first and second vaccinations was 30 to 40 days in cats, for vaccines from both Japanese and foreign manufacturers. In routine cat sera, the peak tended to occur 22 to 49 days after the second vaccination when the interval between vaccinations was 91 days or more, although the reason for this finding remains unclear. In routine cat sera, vaccines from foreign manufacturers tended to elicit higher titers than those from Japanese manufacturers, probably because of the adjuvant effect or amount of inoculated antigen. However, this tendency was not observed in routine dog sera.

In both dogs and cats, the change in antibody titer after the second vaccination was similar to that observed for the routine sera. Therefore, the results from present vaccination tests can probably be treated as general data. From the results above, in both dogs and cats, proper regular vaccination was found to maintain the necessary titer of neutralizing antibodies over the long-term. In addition, inappropriate timing of blood sampling, conducting immediately or at least 50 days after the second vaccination, failed to detect sufficient neutralizing antibody titer as also reported by Kennedy et al. (2007) [8]. Ezoe et al. reported that the third vaccination elicited a spike in the rabies neutralizing antibody titer in both dogs [5] and cats [6] and that the level of neutralizing antibody was maintained for at least a year, even in cases where a low titer was noted at the time of vaccination. Therefore, regular vaccination against rabies in dogs and cats is important for preventing rabies infection. Similar to previous reports $[3,6]$, the present study also showed that the long-term titer of the rabies neutralizing antibody after inoculation with an inactivated rabies vaccine was higher in cats than in dogs. However, this result should be treated a case study, because only beagle dogs were used in the present study.

Kennedy et al. reported that the pass rate in the FAVN test for dogs was highest at 30 days after vaccination [8]. Mansfield et al. reported that the highest pass rate in the FAVN occurred from 1 to 4 weeks after vaccination in dogs and from 4 to 5 weeks after vaccinations in cats [11]. The differences between the previous reports and the present study may be attributed to the number of vaccinations. The present data were analyzed after the second vaccination, whereas previous studies did not limit the number of vaccinations.

In many countries, rabies vaccination is not imposed for cats, and domestic cats can generally roam freely. Considering these situations, the potential risk of cats as a source of rabies infection may be high. Several reports describe prophylaxis against rabies in cats $[1,7,10]$, and transmission of rabies from a bat to a cat has been confirmed [12]. However, at present, few reports are available regarding the efficacy of commercial rabies vaccines in cats. Therefore, the findings 
Table 1. Titer of the rabies neutralizing antibody induced by the inactivated rabies vaccine and the pass rate of the FAVN test under various conditions in routine dog serum samples

\begin{tabular}{|c|c|c|c|c|c|c|c|c|}
\hline \multirow{2}{*}{$\begin{array}{l}\text { Days between } \\
\text { vaccinations a) }\end{array}$} & \multirow{2}{*}{ Vaccine manufacturer } & \multicolumn{7}{|c|}{ Days between second vaccination with inactivated rabies vaccine and blood sampling } \\
\hline & & 0 & $1-7$ & $8-14$ & $15-21$ & $22-28$ & $29-49$ & $\geq 50$ \\
\hline \multirow[t]{6}{*}{$30-40$} & Japanese company & $7.0^{\mathrm{b})}$ & 23.9 & 41.3 & 27.5 & 26.5 & 21.2 & 19.8 \\
\hline & & $5.4^{\mathrm{c})}$ & 3.6 & 1.3 & 0.0 & 0.0 & 1.3 & 3.3 \\
\hline & & $93^{\mathrm{d})}$ & 140 & 224 & 95 & 53 & 75 & 61 \\
\hline & Non-Japanese company & 18.1 & 18.7 & 49.8 & 36.7 & 17.8 & 26.7 & 9.0 \\
\hline & & 0.0 & 5.0 & 0.0 & 1.1 & 4.0 & 1.5 & 7.1 \\
\hline & & 14 & 140 & 121 & 93 & 25 & 69 & 42 \\
\hline \multirow[t]{6}{*}{$41-90$} & Japanese company & 1.9 & 12.2 & 39.0 & 31.3 & 20.9 & 23.2 & 14.3 \\
\hline & & 28.9 & 5.9 & 3.4 & 0.0 & 0.0 & 2.6 & 0.0 \\
\hline & & 45 & 34 & 59 & 36 & 15 & 39 & 23 \\
\hline & Non-Japanese company & 15.9 & 4.8 & 70.2 & 27.9 & 10.6 & 19.0 & 17.4 \\
\hline & & 0.0 & 10.5 & 0.0 & 5.6 & 20.0 & 0.0 & 0.0 \\
\hline & & 5 & 19 & 8 & 18 & 15 & 12 & 16 \\
\hline \multirow[t]{6}{*}{$\geq 91$} & Japanese company & 1.5 & 19.6 & 24.1 & 52.3 & 33.4 & 34.1 & 7.4 \\
\hline & & 29.0 & 4.2 & 2.7 & 0.0 & 0.0 & 0.0 & 11.1 \\
\hline & & 31 & 24 & 37 & 28 & 7 & 16 & 9 \\
\hline & Non-Japanese company & 9.4 & 30.8 & 44.1 & 43.9 & 24.5 & 11.0 & 11.5 \\
\hline & & 0.0 & 0.0 & 0.0 & 0.0 & 0.0 & 0.0 & 0.0 \\
\hline & & 7 & 4 & 16 & 7 & 6 & 7 & 7 \\
\hline
\end{tabular}

a) Interval between the first and second vaccinations. b) Geometric mean of the titer of the rabies neutralizing antibody determined by the FAVN test $(\mathrm{IU} / \mathrm{m} l)$. c) Disqualification rate of the FAVN test (\%). d) Number of samples.

Table 2. Titer of the rabies neutralizing antibody induced by the inactivated rabies vaccine and the pass rate of the FAVN test under various conditions in routine cat serum samples

\begin{tabular}{|c|c|c|c|c|c|c|c|c|}
\hline \multirow{2}{*}{$\begin{array}{l}\text { Days between } \\
\text { vaccinations }^{\text {a) }}\end{array}$} & \multirow{2}{*}{ Vaccine manufacturer } & \multicolumn{7}{|c|}{ Days between second vaccination with rabies inactivated vaccine and blood sampling } \\
\hline & & 0 & $1-7$ & $8-14$ & $15-21$ & $22-28$ & $29-49$ & $\geq 50$ \\
\hline \multirow[t]{6}{*}{$30-40$} & Japanese company & $4.1^{\mathrm{b})}$ & 13.4 & 25.7 & 20.2 & 13.1 & 17.1 & 7.1 \\
\hline & & $16.6^{\mathrm{c})}$ & 8.6 & 2.7 & 5.6 & 4.6 & 3.4 & 14.5 \\
\hline & & $145^{\mathrm{d})}$ & 256 & 475 & 214 & 87 & 176 & 62 \\
\hline & Non-Japanese company & 20.7 & 22.3 & 34.9 & 38.7 & 33.7 & 30.2 & 18.7 \\
\hline & & 4.7 & 1.1 & 1.1 & 0.8 & 1.2 & 0.9 & 2.8 \\
\hline & & 64 & 88 & 179 & 127 & 84 & 116 & 144 \\
\hline \multirow[t]{6}{*}{$41-90$} & Japanese company & 8.4 & 17.2 & 34.7 & 26.2 & 29.6 & 21.9 & 13.5 \\
\hline & & 7.9 & 7.0 & 1.2 & 3.7 & 3.3 & 3.6 & 2.7 \\
\hline & & 38 & 43 & 81 & 54 & 30 & 55 & 37 \\
\hline & Non-Japanese company & 26.4 & 23.4 & 53.0 & 35.7 & 48.1 & 31.0 & 19.9 \\
\hline & & 0.0 & 0.0 & 0.0 & 0.0 & 0.0 & 0.0 & 4.7 \\
\hline & & 21 & 20 & 58 & 35 & 16 & 39 & 42 \\
\hline \multirow[t]{6}{*}{$\geq 91$} & Japanese company & 3.3 & 20.8 & 24.9 & 27.2 & 32.5 & 26.6 & 13.2 \\
\hline & & 30.6 & 4.0 & 6.1 & 4.6 & 5.9 & 0.0 & 8.7 \\
\hline & & 36 & 25 & 66 & 22 & 17 & 17 & 46 \\
\hline & Non-Japanese company & 7.6 & 20.4 & 27.2 & 23.4 & 34.8 & 39.0 & 21.5 \\
\hline & & 5.0 & 0.0 & 0.0 & 0.0 & 0.0 & 0.0 & 0.0 \\
\hline & & 20 & 20 & 33 & 35 & 27 & 41 & 93 \\
\hline
\end{tabular}

a) Interval between the first and second vaccinations. b) Geometric mean of the titer of the rabies neutralizing antibody determined by the FAVN test $(\mathrm{IU} / \mathrm{m} l)$. c) Disqualification rate of the FAVN test (\%). d) Number of samples.

obtained in the present study will be useful as additional information for the efficacy of the rabies vaccine in cats.

In conclusion, the results indicate a detailed change in the rabies neutralizing antibody titer after rabies vaccination in dogs and cats. Based on these data, the proper method of rabies vaccination and timing of acquisition of immunity were determined. This information should be useful for enrichment of the import-export quarantine system for dogs and cats. 


\section{REFERENCES}

1. Blanton, J. D., Dyer, J., McBrayer, J. and Rupprecht, C. E. 2012. Rabies surveillance in the United States during 2011. J. Am. Vet. Med. Assoc. 241: 712-722. [Medline] [CrossRef]

2. Cleaveland, S., Kaare, M., Knobel, D. and Laurenson, M. K. 2006. Canine vaccination-providing broader benefits for disease control. Vet. Microbiol. 117: 43-50. [Medline] [CrossRef]

3. Cliquet, F., Verdier, Y., Sagné, L., Aubert, M., Schereffer, J. L., Selve, M., Wasniewski, M. and Servat, A. 2003. Neutralising antibody titration in 25,000 sera of dogs and cats vaccinated against rabies in France, in the framework of the new regulations that offer an alternative to quarantine. Rev. Sci. Tech. 22: 857-866. [Medline]

4. Dacheux, L., Delmas, O. and Bourhy, H. 2011. Human rabies encephalitis prevention and treatment: progress since Pasteur's discovery. Infect. Disord. Drug Targets. 11: 251-299. [Medline] [CrossRef]

5. Ezoe, S., Ohmori, T., Kusanagi, K., Yasuda, H., Yamanaka, M., Saijo, K. and Takikawa, N. 2007. Efficacy and safety of Japanese rabies vaccine (inactivated) in dogs according to the injection method mandated the import-export quarantine regulation for dogs and other animals. J. Jpn. Vet. Med. Assoc. 60: 873-878.

6. Ezoe, S., Saijo, K., Takikawa, N., Yasuda, H. and Yamanaka, M. 2007. Efficacy and safety of Japanese rabies vaccine (inactivated) in cats according to the import-export quarantine regulation for dogs and other animals. J. Jpn. Vet. Med. Assoc. 60: 805-808.

7. Frymus, T., Addie, D., Belák, S., Boucraut-Baralon, C., Egber- ink, H., Gruffydd-Jones, T., Hartmann, K., Hosie, M. J., Lloret, A., Lutz, H., Marsilio, F., Pennisi, M. G., Radford, A. D., Thiry, E., Truyen, U. and Horzinek, M. C. 2009. Feline rabies. ABCD guidelines on prevention and management. J. Feline Med. Surg. 11: 585-593. [Medline] [CrossRef]

8. Kennedy, L. J., Lunt, M., Barnes, A., McElhinney, L., Fooks, A. R., Baxter, D. N. and Ollier, W. E. 2007. Factors influencing the antibody response of dogs vaccinated against rabies. Vaccine $\mathbf{2 5}$ : 8500-8507. [Medline] [CrossRef]

9. Leung, A. K., Davies, H. D. and Hon, K. L. 2007. Rabies: epidemiology, pathogenesis, and prophylaxis. Adv. Ther. 24: 1340-1347. [Medline] [CrossRef]

10. Lyman, D. 2001. Cat bites: a source of rabies exposure in rural Tennessee. Tenn. Med. 94: 95-97. [Medline]

11. Mansfield, K. L., Burr, P. D., Snodgrass, D. R., Sayers, R. and Fooks, A. R. 2004. Factors affecting the serological response of dogs and cats to rabies vaccination. Vet. Rec. 154: 423-426. [Medline] [CrossRef]

12. Morikawa, V. M., Ribeiro, J., Biondo, A. W., Fellini, A., Bier, D. and Molento, M. B. 2012. Cat infected by a variant of bat rabies virus in a 29-year disease-free urban area of southern Brazil. Rev. Soc. Bras. Med. Trop. 45: 255-256. [Medline] [CrossRef]

13. OIE 2011. Rabies. In: 2011 OIE Terrestrial Manual. Chapter 2.1.13.

14. WHO 1985. Expert Committee on Biological Standards. 35th Report. World Health Organisation Technical Report Series No. 725. 